\title{
A função do dinheiro: uma análise das estratégias dos mediadores em um sistema de crédito cooperativo
}

Jandir Pauli

\& Cinara Rosenfield*

Resumo: Este estudo tem por objetivo compreender como as transações financeiras afetam as relações sociais entre agricultores e dirigentes de cooperativas de crédito que operam recursos disponibilizados por programas governamentais. O problema de pesquisa buscou compreender as estratégias destes dirigentes, denominados mediadores, para articulação do universo simbólico dos agricultores com as expectativas da política pública e do circuito no qual circula o dinheiro oriundo do crédito. Para compreender esta questão foi realizada uma pesquisa empírica em um Sistema de Crédito Cooperativo denominado Cresol. O aporte teórico que orientou a análise das informações articulou os conceitos de frames (McAdam, McCarthy \& Zald, 1999) e de "negociação da intimidade" (Zelizer, 2005). A conclusão é que os mediadores operam uma estratégia de transformação da confiança e da amizade (intimidade) em vínculo institucional. Sua ação adquire um viés instrumental na medida em que converte transações econômicas em intimidade, transferências financeiras em ampliação e fortalecimento da relação social e identidade do sistema.

Palavras-chave: políticas públicas, mediadores, circuitos econômicos, cultura, intimidade.

\section{Introdução}

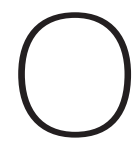

meio rural brasileiro acompanhou, nas últimas décadas, a formação de um novo setor econômico denominado agricultura familiar. Caracterizada tradicionalmente por utilizar mão de obra predominantemente familiar, pela produção diversificada e voltada para o autoconsumo, este setor intensificou sua atividade econômica através do acesso ao crédito público com juros subsidiados, disponibilizado por programas governamentais, passando a produzir para atender demandas de mercado, especialmente de produção de alimentos (Fao/Incra, 1996; Guanziroli \& Cardim, 2000; Uainain, Romeiro \& Guanziroli, 2003; Mattei, 2005; Griza, 2010; Kageyama \& Bergamasco, 2013; Souza-Esquerdo \& Bergamasco, 2014).

Do ponto de vista social, a agricultura familiar foi historicamente caracterizada por manter fortes vínculos comunitários, fazendo emergir uma miríade de associações comunitárias, sindicatos de trabalhadores, cooperativas de produção e de crédito, articuladas especialmente por movimentos sociais, igrejas e organizações não go-
Recebido: 02.07.15

Aprovado: 15.07 .16

\footnotetext{
* Jandir Pauli é graduado em filosofia pela Universidade de Passo Fundo (1998), mestrado em sociologia pela Universidade Federal do Rio Grande do Sul (UFRGS), doutor em sociologia pela Universidade Federal do Rio Grande do Sul, e pós-doutorado em sociologia econômica na Sorbonne - Paris IV. Atualmente é professor titular IV na Faculdade Meridional (Imed) e integra o Programa de Pós-Graduação em Administração, exercendo funções de docente e pesquisador. Coordenador do Grupo de Pesquisas Estudos Organizacionais contemporâneos (CNPq)<jandir@ imed.edu.br> Cinara Rosenfield é graduada em ciências sociais (Universidade Federal do Rio Grande do Sul, 1981), mestrado em sociologia (Universidade Federal da Paraíba, 1983), doutorado em sociologia do trabalho (Université Paris IX - Dauphine, 2000), pós-doutorado (Universidade
} 
Técnica de Lisboa). Atualmente é professora titular da Universidade Federal do Rio Grande do Sul e integra o Departamento de Sociologia e o Programa de Pós-Graduação em Sociologia. Bolsista produtividade CNPq. <rosenfield@uol. com.br>. vernamentais (ONGs). Trata-se de uma definição "fabricada" a partir da relação entre os movimentos sociais e o Estado com o objetivo de reconhecer a importância econômica e social da agricultura familiar (Abramovay, 1992). A ação política dos movimentos sociais contribuiu para criação, em 1996, do Programa Nacional de Fortalecimento da agricultura familiar (Pronaf) (Abramovay \& Bittencourt, 2003).

Em pouco tempo, um expressivo contingente de agricultores familiares passou a acessar o Pronaf através de cooperativas de crédito, credenciadas como agentes financeiros junto ao Banco Central do Brasil (Bacen) (Burigo, 2006). Embora estas centrais tenham surgido por diversos fatores como economia de escala e necessidade de uma maior articulação político-organizativa, ocorre que ainda em 2000 o Bacen orientou a criação de centrais de cooperativas (sistemas) com a função administrativa de articular e monitorar as movimentações financeiras de todas as cooperativas vinculadas, as chamadas cooperativas singulares. Isso facilitou o controle uma vez que essas centrais foram obrigadas a reunir todas as informações sobre as cooperativas singulares, além de corresponsabilizá-las pela gestão adequada às regras do Sistema Financeiro Nacional (SNF) (Búrigo, 2007).

No percurso entre a criação das cooperativas de crédito, seu credenciamento como parceiras governamentais repassadoras de recursos públicos e a criação das centrais de cooperativas surgem os mediadores. Quem são os mediadores? São diretores, assessores e técnicos que integram as cooperativas de crédito e estão localizados em espaços estratégicos de gestão, atuando na elaboração e coordenação de projetos e no acompanhamento e controle na aplicação dos recursos. Esta condição permite aos mediadores um relacionamento permanente com os agricultores familiares tomadores de créditos, possibilitando sua atuação para alinhar as estratégias das políticas públicas com a missão institucional das cooperativas e as expectativas dos agricultores beneficiários do Pronaf.

A importância de analisar a ação dos mediadores deve-se à sua particular responsabilidade de elaborar, propor e articular visões de mundo, valores, sentimentos, significados e ideologias, que, associados à racionalidade econômica, contribuem para a mobilização coletiva e a demarcação do contexto em que as ações dos agricultores se desenvolvem (McAdam, McCarthy e Zald, 1999).

Este estudo explora as transformações nas relações sociais ocorridas na agricultura familiar a partir da intensificação da utilização do crédito. Para analisar estas transferências, a socióloga estadunidense Viviana Zelizer elabora uma ferramenta analítica denominada circuito econômico (Zelizer, 2002; 2005a, 2010a, 2010b). Entende-se por circuito uma configuração social e econômica que permite a circulação de 
acordos, práticas, informações, instrumentos de troca e símbolos partilhados neste ambiente. Cada circuito é caracterizado por: (1) limites mais ou menos precisos e algum controle sobre suas fronteiras; (2) laços pessoais significativos entre seus membros; e (3) transações econômicas próprias e instrumentos de troca com base na reciprocidade (Zelizer, 2005a: 96).

Nestes circuitos, os atores estabelecem uma "negociação da intimidade" (Zelizer, 2005b). Para a autora, a noção de intimidade incorpora três dimensões: (1) confiança; (2) reciprocidade; e (3) amizade. Além disso, existem dois tipos de negociação da intimidade: (1) transferência de informações confidenciais e potencialmente "minadas"; e (2) laços estreitos duráveis entre duas pessoas. É nesta intimidade que ocorrem as transferências econômicas (Zelizer, 2005b) e é por esse motivo que negociar a intimidade torna-se um objetivo de primeira grandeza para o ajuste da relação social. Em outros termos, a negociação da intimidade é operada em um circuito econômico onde os mediadores buscam conquistar a confiança e a amizade dos agricultores para consolidarem as estratégias institucionais.

A construção da problemática de pesquisa partiu das seguintes perguntas:

Como ocorre a análise, a concessão e o acompanhamento do crédito? Como os mediadores se aproximam das famílias e como constroem a fidelização do agricultor?

Como a amizade entre agricultores e diretores trata temas como acompanhamento e controle da aplicação dos recursos?

Quais são as práticas que sustentam a relação entre os mediadores e as famílias associadas?

Como símbolos e rotinas colocam os atores em relação?

Qual é a base da confiança no circuito?

A partir dessas perguntas, este estudo busca problematizar como elementos da intimidade são misturados às transações econômicas a partir da ação dos mediadores para oferecer suporte simbólico às práticas econômicas nos circuitos.

O objeto empírico deste estudo é um Sistema de Cooperativas de Crédito com Interação Solidária, denominado Cresol Central SC/RS. Com sede na cidade de Chapecó (SC), o sistema articula em uma central, mais de 60 cooperativas com mais de 100 mil associados. Para consecução dos objetivos foram utilizados métodos de análise qualitativa a partir da organização de um corpus de pesquisa (Bauer 
\& Gaskell, 2002: 44-45) constituído por 25 entrevistas semiestruturadas e pelos registros coletados a partir da observação das práticas em encontros formativos e assembleias gerais do sistema. Para tratamento das informações, foi utilizada a análise de conteúdo (Bardin, 2011) que classificou os dados coletados a partir das entrevistas e da observação, avaliando a presença ou a ausência de determinados temas (Pereira, 1998: 106) e sua categorização para discussão à luz dos pressupostos teóricos da pesquisa.

\section{Crédito, circuitos econômicos e intimidade}

Um dos argumentos teóricos deste estudo é que as políticas públicas criam novos mercados caracterizados por transações econômicas específicas. A ideia de "mercados" se opõe à interpretação usual da ciência econômica que se apoia na noção mercado homogeneizante, totalizante e racionalizante. Nesta visão, o mercado é o resultado linear da utilização extensa do dinheiro que teve por consequência a abertura da unidade doméstica e o desenvolvimento das trocas despersonalizadas (Weber, 2000).

Embora este estudo compartilhe da ideia de que o dinheiro é um vetor social de primeira grandeza, sua perspectiva diverge da visão da ciência econômica quando sugere que ao invés de existir "o dinheiro de mercado" existem "dinheiros especiais" (Zelizer, 2003) que funcionam como meios de troca, mas também como classificadores sociais e sagrados em diferentes contextos, utilizados para adquirir ou melhorar o status, ou para celebrar rituais. Estes "dinheiros" estão amparados em cinco pressupostos:

1. funcionam como meio de troca, existindo, também, fora do mercado e moldado por fatores culturais e socioestruturais;

2. existem uma multiplicidade de dinheiros e todos eles são condicionados por uma realidade específica;

3. existem diferentes tipos de dinheiro, indivisíveis quanto à quantidade, não fungíveis, não portáteis, profundamente subjetivos e qualitativamente heterogêneos;

4. não há dicotomia entre valores utilitaristas e não pecuniários; e

5. a cultura e a estrutura social impõem os limites da utilização do dinheiro, isto é, fatores "extraeconômicos" constrangem e moldam sua utilização, a saber: (a) o dinheiro é usado para atividades específicas; (b) pessoas específicas são designadas para operar o dinheiro e; (c) há formas específicas de controle do dinheiro (Zelizer, 2003: 136). 
Assim, Zelizer (2007) rompe com o tradicionalismo econômico que confere ao dinheiro um caráter neutro do ponto de vista cultural. Assim, este estudo incorpora a perspectiva de que o dinheiro não é um "solvente" devastador e uniformizador que nivela as relações sociais por onde ele passa. Da mesma forma, o dinheiro não está isolado das relações não econômicas, mas enraizado em "redes sociais" particulares que fornecem o fundamento da significação social (Zelizer, 2007).

Ao analisar relações sociais mediadas pelo crédito como um tipo de dinheiro, este estudo sugere que sua utilização, além de expor as famílias ao contexto do mercado, altera as relações sociais entre os integrantes do circuito por onde o crédito circula. Em outros termos, busca-se compreender como referenciais culturais são "arranjados" nas relações sociais do interior do circuito, ao mesmo tempo em que transmitem pautas coletivas.

Quatro elementos estão em jogo neste processo: (1) as relações (acordos, práticas e obrigações); (2) as transações (interações limitadas em duas pessoas); (3) os meios de troca (sistema computáveis que recorrem a moedas simbólicas); e (4) as linhas de partilhas (perímetros que delimitam as combinações singulares das relações, das transações e dos meios).

\footnotetext{
Cada circuito distinto incorpora o entendimento um pouco diferente das práticas de informação, obrigações, direitos, símbolos e meios de troca. Eu chamo esses circuitos de comércio em um sentido antigo da palavra, onde comércio significava conversação, intercâmbio, relações e modelagem mútua. Variam desde a mais íntima à mais impessoal das transações sociais (Zelizer, 2002: 4-5, tradução livre).
}

As características dos circuitos econômicos podem ser resumidas em cinco pontos: (1) comportam diferentes relações sociais entre os indivíduos específicos; (2) permitem compartilhar as atividades econômicas realizadas por essas relações sociais, isto é "os laços entre os participantes têm o significado compartilhado"; (3) criam sistemas de contabilidade comuns para avaliar o intercâmbio econômico, por exemplo, formas particulares de dinheiro; (4) compartilham os significados que as pessoas atribuem a suas atividades econômicas, isto é, "um conjunto distinto de transferência de bens, serviços ou reivindicações dentro de seus laços interpessoais"; e, por fim, (5) estabelecem uma fronteira clara entre os membros do circuito e os não membros, com algum controle sobre as transações que atravessam a fronteira (Zelizer, 2010a: 315). Desta forma os circuitos apresentam limites mais ou menos precisos e algum tipo de controle sobre as transações que acontecem além de suas fronteiras. Essas transações estão apoiadas em laços interpessoais que partilham 
significados e cada circuito econômico é um tipo de agenciamento entre a intimidade e a economia de cada espaço da vida social.

A partir deste ponto, ao procurar estabelecer uma ponte entre intimidade e economia, a autora aponta duas ferramentas analítico-conceituais para analisar a questão: a ideia de "cruzamentos" e de "boas combinações" (Zelizer, 2005a: 22). Cruzamentos são "encontros" entre as diferentes esferas da vida e se desenvolvem de duas maneiras: pela especificidade da relação (neste caso, agente de crédito e tomador) e pela adoção de práticas (formas de pagamento, rotinas, elaboração e monitoramento de aplicação dos recursos financeiros etc.). Nestes "cruzamentos" entre intimidade e economia, mediadores e agricultores estabelecem "boas combinações" que permitem a incorporação de novas oportunidades econômicas e comerciais sem que essas prejudiquem as relações de confiança. Em outras palavras, "boas combinações" são arranjos realizados entre as pessoas valendo-se de duas estratégias: primeiro elas definem o tipo de relação (pais e filhos, professores e alunos) e, em seguida, adotam práticas, rituais e símbolos para o ajuste da intimidade com a racionalidade econômica. É desta capacidade que resultam as "boas combinações".

Com base nesses pressupostos, este estudo explora as relações sociais mediadas pelo crédito em circuitos econômicos onde a formatação da identidade e os limites são definidos pelos mediadores. Por isso, avaliar sua ação permite compreender o processo de elaboração, proposição e articulação de visões de mundo, valores, significados e ideologias, que associados à racionalidade econômica, contribuem na mobilização coletiva e atribuição de sentido à ação social.

\section{Mediadores e gestão do crédito}

Dough McAdam, John McCarthy e David Zald (1999), a partir das elaborações de David Snow e Robert Benford (1992), propõem os conceitos de frames (marcos interpretativos) como articulação entre a ideologia dos movimentos sociais e a dimensão cognitiva de seus integrantes. Para Zald (1999: 370) a relação entre os movimentos, a criação de "marcos interpretativos" e a sociedade em geral é mutuamente afetada por seis pontos: (1) a construção cultural de repertórios de argumentos e os marcos nos quais se enquadram; (2) as contradições culturais e os sucessos históricos que permitem levar adiante o processo de "encaixe"; (3) a criação de "marcos interpretativos" como atividade estratégica dos movimentos; (4) os processos competitivos que resultam na escolha de um marco interpretativo dominante; (5) a difusão dos marcos por meios de comunicação, especialmente de massa; e (6) o confronto entre as oportunidades políticas e a mobilização para dar forma ao resultado das lutas entre os diferentes marcos. 
A ideia desta perspectiva é de que a cultura atue como "processo de encaixe" em um

processo ativo de criação de "marcos interpretativos" e definição de ideologias, dos símbolos e dos eventos icônicos que são levados a cabo pelos inovadores da moral, que podem ser ativistas ou não (Zald, 1999: 380).

Os atores fazem referência ao conceito de "processos de encaixe", também desenhados por Snow, e definidos como

esforços estratégicos conscientes realizados por grupos de pessoas para forjar várias formas compartilhadas de considerar o mundo e a si mesmas, que legitimem e movam a ação coletiva (McAdam, McCarthy \& Zald, 1999: 27).

Em outros termos, os mediadores seriam responsáveis pela elaboração, articulação e proposição de referenciais que buscam definir, justificar e legitimar as práticas sociais nos circuitos econômicos. Esses referenciais de mundo são negociados e sofrem a influência dos valores e da visão de mundo dos agricultores, sendo permanentemente atualizados e institucionalizados.

Nesta direção, os mediadores operam a ambivalência entre "fechamento" e "abertura" do circuito, o que significa fechá-lo do ponto de vista da circulação do dinheiro (ampliação dos produtos e serviços disponibilizados aos associados para evitar que o dinheiro saia das divisas do circuito) e, ao mesmo tempo, manter sua comunicação com o exterior, incorporando novos símbolos, sentimentos, inovações organizacionais e significados que passam a ser negociados com agricultores. Por essas razões, estabelecer relações de intimidade com os agricultores torna-se uma importante estratégia para a consolidação dos objetivos da política pública e da missão do sistema.

O sistema de crédito em questão pode ser qualificado como um circuito econômico. Neste sentido, a ação dos mediadores na formação da Cresol parece estar orientada para a criação de uma complexa rede de significados que mesclam elementos de ordem (1) política (simetria nas relações de poder, proximidade com a realidade do agricultor, linguagem acessível e orientação do crédito);(2) cultural (importância da família, cooperação e ajuda mútua); (3) econômica (juros mais baixos, acompanhamento técnico, financiamento desburocratizado da produção e do consumo); e (4) afetiva (confiança, reciprocidade, amizade e cuidado/zelo). Além disso, na organização desse circuito, o crédito emerge como principal meio de articulação entre a di- 
mensão racional/instrumental com um sistema de valores que identifica e demarca as fronteiras entre as transações econômicas e não econômicas.

\section{Método}

Para compreender as relações sociais entre dirigentes do Sistema Cresol e os agricultores foram utilizados métodos de análise qualitativa. Um corpus de pesquisa (Bauer \& Gaskell, 2002: 44-45) foi constituído por 25 entrevistas semiestruturadas e pelos registros coletados a partir da observação das práticas em encontros formativos e assembleias gerais do Sistema Cresol SC/RS. A escolha dos participantes foi realizada por conveniência e as entrevistas ocorreram nas cooperativas, nos encontros de formação e nas propriedades dos agricultores, sendo divididas em dois grupos: (1) o primeiro, composto por 17 mediadores (nove diretores (DIR), três assessores de formação (ASR) e cinco técnicos (TEC)); e (2) o segundo, por oito agricultores associados em diferentes cooperativas.

A segunda técnica de coleta de dados utilizada foi a observação (Becker, 1994). A estrutura organizativa do Sistema Cresol SC/RS utiliza os encontros periódicos e as assembleias gerais para prestação de contas, socialização de informações e planejamento das ações. A coleta de dados ocorreu em duas assembleias anuais, dois seminários de planejamento estratégico, uma oficina de formação e nas rotinas diárias de funcionamento das cooperativas.

Essa articulação entre duas técnicas de coleta de dados permitiu observar a aproximação entre as compreensões individuais e as expectativas organizacionais, procurando compreender como as práticas são estruturadas. O tratamento das informações foi realizado utilizando a análise de conteúdo (Bardin, 2011) que classificou os dados coletados a partir das entrevistas e da observação em um enfoque qualitativo, analisando a presença ou a ausência de determinados temas (Pereira, 1998), conforme será demonstrado a seguir.

\section{A ação dos mediadores no Circuito Cresol}

A partir da análise das entrevistas e da observação, foi possível evidenciar que a atuação dos mediadores está orientada em dois sentidos: (1) proporcionar "boas combinações" entre a racionalidade instrumental e o universo dos valores dos agricultores; e (2) valer-se das relações de intimidade para consolidar as estratégias organizacionais do sistema de crédito, configurando-o como um circuito econômico específico com capacidade de controle sobre as operações financeiras dos associados. 


\section{Racionalidade instrumental,}

valores e significado do crédito

A análise dos dados evidenciou que a aproximação entre agricultores familiares e mediadores tem como objetivo significar as transações monetárias e produzir a confiança necessária para a reelaboração constante e manutenção do circuito. A resposta de um técnico ilustra bem esta questão. Perguntado sobre como a Cresol deveria atuar, sua sugestão é:

Na transparência e no convívio com o associado, mostrar que a Cresol faz parte dele; que o associado é dono disso aqui também. Você tem que ter um carisma com ele, tem que tratar ele bem (TEC2).

Outro diretor ratificou esta ideia ao afirmar:

A gente tem um trabalho de antes de liberar o crédito ir lá e fazer uma visita, conversar com o agricultor, se aquilo que ele quer financiar realmente está precisando (DIR3).

Esta aproximação permite estabelecer relações de intimidade com os agricultores para demarcar o significado e a finalidade da utilização do crédito, além de produzir o convencimento necessário para reformular e atualizar os frames do circuito. Perguntado sobre como o crédito afeta o sistema, um diretor responde:

O dinheiro vai te fazendo mudar de pensamento, mudar a organização. Tu vai percebendo que a organização precisa sobreviver no mercado, e para isto precisa mudar os pensamentos, os valores, as crenças e etc. (DIR5).

A fala de outro diretor aponta para a mesma direção:

O dinheiro pode alterar as relações se você não trabalhar a lógica de para que ele serve, para que que ele entra na propriedade? Porque você recebe a lógica individualista de fora, que não é uma coisa construída ali na família (DIR7).

A resposta de um técnico corrobora as opiniões acima:

Infelizmente está virando uma questão mais financeira. Conforme a cabeça pensante, ele pode te reascender na vida, ou conforme a cabeça pensante, ele pode te matar. É uma arma! É uma arma perigosa (TEC2). 
Estes depoimentos demonstram o esforço dos mediadores para articularem dois mundos aparentemente hostis: a racionalidade econômica e o universo dos valores. A estratégia para isto é investir na criação de relações de proximidade como forma de evitar que a lógica instrumental-financeira se sobreponha ao sistema de significados partilhados no circuito. Em outros termos, são as relações de intimidade que permitem a marcação do dinheiro oriundo do crédito e a consequência política desta marcação é um ganho institucional bastante significativo, uma vez que constituiu a Cresol Central SC/RS como "diferente" das outras instituições financeiras. Perguntado sobre como as famílias gerenciam o dinheiro e se a Cresol orienta a utilização do dinheiro, um diretor responde:

\footnotetext{
A gente entra com recursos, crédito, financiamento para melhorar a propriedade. Tem que ver como é que tu interfere, mas sabendo do passado daquela família, o que aconteceu lá, você consegue interferir nisso (DIR6).
}

Este depoimento ilustra o argumento de que os mediadores utilizam o crédito para interferirem na organização da propriedade. Embora o crédito e a gestão racional tenham provocado mudanças profundas na organização econômica e social, essas mudanças não eliminaram as dimensões da intimidade e as novas combinações arranjaram e reestruturaram as relações sociais através da significação do dinheiro. Os mediadores, quando questionados sobre essas transformações, geralmente procuram articular elementos que reconhecem os impactos "racionais" na gestão da unidade doméstica com elementos simbólicos de significação do crédito e preservação dos laços sociais.

Como essas agudas transformações afetam a organização doméstica, especialmente da unidade familiar rural, no sentido das relações sociais e afetivas entre seus membros? Como estes indivíduos irão arranjar/combinar as novas necessidades e a manutenção dos laços sociais? É neste contexto que emergem os mediadores com a tarefa de propor símbolos e quadros de referência - frames - para articular a manutenção dos laços sociais com os novos elementos técnico-instrumentais, específicos da relação com o mercado. O "crédito assistido" passa a ser uma importante ferramenta no contexto do aumento da circulação de dinheiro, da abertura da unidade doméstica e da preservação dos laços sociais.

Hoje a maioria é assim: o pessoal vem para buscar um recurso, e a gente sempre procura conversar com ele né, saber por que ele quer aquele recurso, se vale a pena ou não vale esse tipo de investimento que ele quer fazer. Se vai ter retorno ou não, se vai ter mercado para isso, ou não. Então a gente procura fazer uma boa 
conversa na cooperativa e, e em alguns casos, a gente vai na propriedade e conversa; ver se ele tem capacidade para isso (DIR7).

A partir dos argumentos até aqui apresentados, pode-se apontar que a definição de dinheiro proposta pelos mediadores raramente menciona sua função técnica, isto é, sua capacidade de ampliar o capital e os rendimentos dos agricultores. Sua intenção é fornecer um conceito que vincule a necessidade prática dos agricultores com uma rede de significados partilhados no Circuito Cresol SC/RS. Em outros termos, os mediadores fornecem o conteúdo que identifica e diferencia o Sistema Cresol das demais instituições financeiras, sejam sistemas cooperativos ou bancos convencionais. Essas conclusões, além de reforçarem a ideia de Zelizer sobre a relação entre mundos aparentemente hostis, mostram também as motivações políticas dos mediadores e seus esforços para combinarem ganhos financeiros dos associados com o fortalecimento da organização em que atuam, beneficiando-se desses resultados. As conclusões também reforçam a teorização de McAdam, McCarthy e Zald (1999) ao encontrar evidências de que os mediadores atuam no alinhamento (articulação) entre os valores, os sentimentos, as visões de mundo e a pretensão de legitimidade da política pública com os quadros de referência dos agricultores associados (beneficiários). Em termos práticos, os mediadores são responsáveis pelo alinhamento entre: (a) a missão das políticas públicas e das linhas de financiamento dos bancos de investimento - fonte dos recursos econômicos - e/ou mesmo da captação de recursos a partir das cotas de capital e de depósitos dos associados; (b) a missão das cooperativas; $(c)$ a proposição de símbolos que permitam a associação entre a dimensão política e social do crédito com a atividade econômica das famílias; e (d) a ampliação da reciprocidade e confiança na relação com os agricultores.

\section{Intimidade, intersecções \\ e consolidação do sistema}

Um segundo aspecto basilar, obtido através da observação das práticas diárias nas cooperativas, é que as relações de crédito estabelecem uma relação assimétrica entre quem concede e quem contrata o dinheiro. Isto se explica porque o agricultor que deseja receber o crédito precisa argumentar sobre os reais motivos que o levam a solicitar o crédito e fornecer um volume considerável de informações pessoais. Soma-se a isto o fato de os funcionários das cooperativas buscarem informações sobre possíveis restrições de crédito, verificando se o candidato está em dia com eventuais dívidas contraídas em outras instituições financeiras ou casas de comércio.

Questionados sobre o volume de informações (conhecimento) acerca dos associados, os mediadores entrevistados informaram que geralmente conhecem todos ou 
a grande maioria e marcaram este aspecto como principal diferencial do Circuito Cresol em relação a outras instituições financeiras. O conhecimento sobre as transações financeiras (vida econômica) passa a ser o elo de articulação entre a economia e a intimidade. Em outras palavras, a relação de crédito tratará de ajustar este conhecimento para que não prejudique a relação entre ambos. A partir desta diferenciação, é estabelecido um conjunto de direitos e deveres. A transparência e o compromisso ético com as informações disponíveis sobre a intimidade estão no lastro destas convenções de garantia de estabilidade das relações sociais no circuito.

A confiança histórica entre "diretores" e "agricultores" que tem origem nas relações de proximidade política e comunitária, passa agora a incorporar uma transação econômica com a intensificação da utilização do dinheiro, na introdução do cálculo, de novas ferramentas de gestão e de protocolos organizacionais que afetam substancialmente a relação. A diferenciação e a demarcação da relação cumprem a expectativa de que esta relação não seja corrompida pelas oportunidades (acesso ao crédito) e/ou ameaças do contexto (falência da cooperativa, despersonalização da relação e não pagamento da dívida contraída) e contribua para ampliar e solidificar os laços sociais.

Neste sentido, a lógica financeira passa a conviver com as relações de amizade e a linha que separa relações de intimidade expressas pela ideia de amizade torna-se o elo da fidelização entre associados e suas cooperativas. Por outro lado - como aponta Zelizer -, no cotidiano as pessoas se esforçam significativamente para demarcar o tipo de relação em que estão e como o dinheiro entra nesta relação. Questionados sobre a interferência das relações de amizade na efetivação dos contratos, as repostas apontam para a mesma direção:

A gente não pode misturar amizade com negócios. Então a nossa amizade não vai interferir numa liberação de crédito. Então você consegue ir lá e ter uma amizade com o fulano, mas a parte da cooperativa é um negócio à parte (DIR9).

Outro diretor entrevistado afirmou:

No meu caso não tem muita dificuldade porque eu penso que amizade é amizade e negócio é negócio. Assim, na hora que estamos fazendo negócios eu vou procurar fazer o melhor negócio para a cooperativa e também vou entender o teu lado (DIR3).

Os agricultores também reforçam esta lógica: 
Eu conheço todo mundo aqui. São amigos e tudo, de fato. De banco e tudo. Não há problema. E a amizade também por fora do banco é mesma que dentro. Não, não tem diferença. No banco e fora é a mesma pessoa (AGR6).

Outro agricultor, perguntado se tem amigos que trabalham na operação do crédito responde:

Tenho, tenho, tenho. Tem esse "piazão" ali. Quando a gente negocia alguma coisa a gente cai direto na Cresol. É o cara que a gente chega ali e pode conversar. A gente tem uma amizade já de tempo. Nunca brigamos por causa disso, a relação sempre foi boa (AGR4).

Da mesma forma, a diferenciação e a demarcação contribuem para a definição da relação com os "novos" associados. É importante levar em consideração que, neste caso, à primeira vista, o fato que motiva esta aproximação parece ser um elemento de ordem puramente racional: o agricultor procura crédito com juros baixos para ampliar a sua renda e seu capital. No entanto, neste percurso, mesmo que as relações de crédito pareçam impessoais, elas produzem uma relação de longo prazo expressa pelo compromisso da dívida, deslocando a questão da intimidade (produção de confiança) para a base da compreensão da relação de crédito.

Neste sentido, esta pesquisa levou em consideração a aproximação e a produção de confiança e reciprocidade no âmbito das quais o agricultor terá de fornecer informações que até então pertenciam ao grupo social restrito, ou até mesmo unicamente à sua família. De posse desse conteúdo, os diretores buscam outras informações de ordem econômica, como os antecedentes comerciais e informações públicas úteis para contribuir na tomada de decisões. Através da observação do funcionamento rotineiro das cooperativas, percebeu-se também que são levadas em consideração outras informações de caráter pessoal e de comportamento social. Além disto, são observadas, por exemplo, a idoneidade moral e a estrutura familiar do associado. Perguntado sobre que tipos de informações são buscadas, um dos diretores responde:

Desde a questão pessoal dele, como ele é na sociedade; se é uma pessoa que hoje cumpre suas obrigações; se é uma pessoa bem vista, que batalha, que luta. Também como ela se relaciona com a sociedade (DIR6).

Para outro diretor, a relação de confiança permite que o próprio agricultor preste as informações necessárias: 
Tem o agricultor que vai na cooperativa para conversar contigo porque a Cresol tem essa, ele confia na Cresol. Os problemas que ele não fala para outras pessoas ele vem e a gente fica sabendo (DIR3).

Em outros termos, embora ambos reconheçam a necessidade de demarcação e diferenciação das relações de amizade com as de negócios, geralmente as fronteiras entre as duas esferas são superadas e se confundem o tempo todo. É neste ponto que os pressupostos teóricos podem ser confirmados: no Circuito Cresol SC/RS os mediadores operam a estratégia de converter laços de proximidade, confiança e amizade em vinculação institucional, da mesma forma que a lógica financeira afeta e altera uma relação social preexistente às relações de crédito. Sua ação adquire um viés instrumental na tentativa de converter transações econômicas em intimidade, transferências financeiras em ampliação e fortalecimento da relação social. É por este motivo que o estabelecimento de relações de intimidade com os agricultores torna-se um objetivo de primeira grandeza para o ajuste da relação social e atualização dos limites morais do circuito.

\section{Conclusões}

O pressuposto geral deste estudo é de que os mediadores fornecem o conteúdo simbólico que permite combinar a lógica financeira com os referenciais culturais e os elementos da intimidade dos agricultores para fortalecer as relações sociais e a identidade do Circuito Cresol SC/RS. Para isto, atuam em quatro frentes: (1) definem o circuito (suas fronteiras e sua identidade); (2) desenvolvem ações para captar a intimidade dos agricultores, convertendo a confiança, a reciprocidade e a amizade em fortalecimento da organização e benefícios econômicos e sociais para os agricultores; (3) elaboram os significados do dinheiro; e (4) negociam o significado do dinheiro com os agricultores. Essa negociação com os agricultores não é um movimento de imposição, mas de adaptação permanente entre as mudanças da atuação da organização, a expectativas dos agricultores e a motivação particular dos mediadores. Neste sentido, os mediadores são atores-chave do circuito porque transitam entre a lógica institucional ao mesmo tempo em que captam as expectativas dos agricultores. As atualizações (inovações) são o resultado da combinação entre a comunicação do circuito com o exterior e o interesse dos associados.

A análise das informações coletadas reforça a ideia de que o dinheiro não é um solvente das relações sociais entre mediadores e agricultores, embora a utilização extensa do dinheiro tenha alterado a estrutura organizativa e obrigado os mediadores a elaborarem novos quadros de referência para a preservação da identidade do 
circuito e das relações sociais dos seus integrantes. Neste sentido, os mediadores fornecem o conteúdo simbólico que permite combinar a lógica financeira com os referenciais culturais e elementos da confiança dos agricultores para fortalecer as relações sociais e a identidade dos circuitos econômicos em que se inserem. Para isto, atuam em quatro frentes: (1) definem o circuito (suas fronteiras e sua identidade); (2) desenvolvem ações para converter relações de confiança em fortalecimento da organização; (3) elaboram os significados do dinheiro; e (4) "arranjam" o significado do dinheiro com os agricultores.

Do ponto de vista estritamente econômico, o Sistema Cresol SC/RS parece somente cumprir um papel de inclusão dos agricultores familiares no modelo tradicional de mercado, reforçando a ideia de avanço do mercado sobre um espaço antes inexplorado. No entanto, esta ideia não se sustenta porque há evidências de um trabalho relacional entre mediadores e agricultores para que o circuito estabeleça a função social do crédito, tornando-o capaz de transportar significados e ideologias. Em outros termos, ao passo que serve de suporte para as relações sociais, o dinheiro permite que o circuito econômico forneça elementos norteadores da ação coletiva.

Por fim, este estudo conclui que o dinheiro põe em circulação um sistema de valores que significa sua utilização e regula sua circulação. Neste sentido, os mediadores agem sob a ameaça de que o relaxamento da significação do dinheiro cause uma abertura do circuito e sua descaracterização. Para isto, os seguintes temas são reformulados e adaptados constantemente: (1) a submissão às regras do sistema monetário nacional (especialmente as normas do Banco Central); (2) as relações hierárquicas de poder geradas pelo contrato/dívida; (3) a individualização das relações (CPF, conta corrente, crédito por família); (4) a racionalidade e o cálculo na gestão econômica dos financiamentos e da propriedade familiar; (5) o risco de enfraquecimento do comunitarismo e do cooperativismo; e, por fim, (6) a despersonalização das relações sociais diante da expansão geográfica e numérica do sistema.

Entre as lacunas deste estudo, o que sugere agendas de pesquisa futuras, está a opção em não abordar o tema do conflito como tema central. De fato, o aporte teórico utilizado não aponta para análise das consequências negativas que as relações monetárias podem proporcionar. Desta forma, acredita-se que este estudo oferece um ponto de partida para o aprofundamento de uma interessante agenda de pesquisa para analisar relações arruinadas pelo dinheiro ou arranjos não exitosos entre dinheiro e intimidade, como inadimplência, endividamento e quebra de contrato. Com isto, poder-se-ia ampliar a compreensão sobre a complexa relação entre intimidade e transações econômicas. 
Ademais, embora este estudo tenha seguido a trilha culturalista, é necessário aprofundar a relação entre intimidade e transações econômicas, procurando evitar a ideia de que o sistema coletivo de significados e símbolos teria a capacidade de subjugar a economia. Também é preciso ponderar a potência da intimidade como fator preponderante para enquadramento das transações econômicas.

Abstract: This study aims to understand how financial transactions affect social relationships between farmers and directors of credit unions operating resources provided by government programs. The problem of research sought to understand the strategies of these leaders, called mediators, to articulate the symbolic universe of farmers, with the expectations of public policy and the circuit where the money flows. To understand this issue an empirical research was carried out in a Cooperative Credit System called Cresol. The theoretical framework that guided the analysis of the information articulated the concepts of frames (McAdam, McCarthy and Zald, 1999) and "negotiation of intimacy" (Zelizer, 2005). The conclusion is that the mediators operate its strategy of making trust and friendship (intimacy) on institutional affiliation. Its action acquires an instrumental bias in that converts economic transactions in intimacy, financial transfers in expanding and strengthening social relations and identity system.

Keywords: Public Policies, Mediators, Economic Circuits, Culture, Intimacy.

\section{Referências}

ABRAMOVAY, Ricardo. Paradigmas do capitalismo agrário em questão. São Paulo: Hucitec, 1992.

ABRAMOVAY, Ricardo; BITTENCOURT, Gilson. Inovações institucionais no financiamento da agricultura familiar: o Sistema Cresol. Revista Economia Ensaios, v. 16, n. 1, p. 179-207, Uberlândia, 2003.

BARDIN, L. Análise de conteúdo. Lisboa, Portugal: Edições 70, 2011.

BAUER, Martin; GASKELL, George. Pesquisa qualitativa com texto, imagem e som: um manual prático. Petrópolis: Vozes, 2002.

BECKER, Howard. Métodos de pesquisa em ciências sociais. 2. ed. São Paulo: Hucitec, 1994.

BERGAMASCO, Sonia M. P. P., BORSATTO, Ricardo S.; SOUZA-ESQUERDO, Vanilde F. S. Políticas públicas para a agricultura familiar no Brasil: reflexões a partir de estudos de casos no estado de São Paulo. Revista Interdisciplinaria de Estudios Agrarios, n. 38, p. 25-50, 2013.

BÚRIGO, Flavio L. Cooperativa de crédito rural: agente de desenvolvimento local ou banco comercial de pequeno porte? Chapecó: Argos, 2007. 
- Finanças e solidariedade: uma análise do cooperativismo de crédito rural solidário no Brasil. Tese (Doutorado em Sociologia Política) - Centro de Filosofia e Ciências Humanas, Universidade Federal de Santa Catarina, Florianópolis, 2006.

GUANZIROLI, Carlos E.; CARDIM, Silvia. E. de C. S. Novo retrato da agricultura familiar. O Brasil redescoberto. Projeto de Cooperação Técnica Incra/Fao. Brasília: Incra; Fao; MDA, 2000.

GRISA, Cátia. As políticas para a agricultura familiar no Brasil: um ensaio a partir da abordagem cognitiva. Desenvolvimento em Debate, v. 1, n. 2, p. 83-109, 2010.

INCRA/FAO. Perfil da agricultura familiar no Brasil: dossiê estatístico. Projeto UFT/ BRA/036/BRA. Ago. 1996.

KAgEyAMA, Angela. A., BERGAMASCO, Sonia M. P. P.; OLIVEIRA, Julieta. T. A. Uma tipologia dos estabelecimentos agropecuários do Brasil a partir do censo de 2006. Revista de Economia e Sociologia Rural, v. 51, n. 1, p. 105-122, Jan..Mar. 2013.

McADAM, Doug.; McCARTHY, John; ZALD, Mayer (Eds.). Movimientos sociales: perspectivas comparadas. Madrid: Istmo, 1999.

MATTEI, Lauro. Impactos do Pronaf: Análise de Indicadores. "Série Estudos 11 Nead". Brasília: Núcleo de Estudos Agrários e Desenvolvimento Rural; Ministério do Desenvolvimento Agrário, 2005.

PEREIRA, L. Helena. Análise de conteúdo: um approach do social. Cadernos de Sociologia, v. 9, p. 87-114, Porto Alegre, 1998.

SOUZA-ESQUERDO, Vanilde F.; BERGAMASCO, Sonia M. P. P. Análise sobre o acesso aos programas de políticas públicas da agricultura familiar nos municípios do circuito das frutas (SP). Rev. Econ. Sociol. Rural [online], v. 52, sup. 1, p. 205-222, 2014.

SNOW, David; BENFORD, Robert. Master Frames and cycles of protest. in MORRIS, Aldon; MUELLER, Carol. Frontiers in social movement theory. New Haven: Yale University Press, 1992.

UAINAIN, Antônio M.; ROMEIRO, Ademar R.; GUANZIROLI, Carlos. Agricultura familiar e o novo mundo rural. Sociologias, n. 10, p. 312-347, 2003.

ZALD, Mayer. Cultura, ideología y creación de marcos estratégicos. In: McADAM, Doug; McCARTHY; John; ZALD, Mayer. Movimientos sociales: perspectivas comparadas. Madrid: Istmo, 1999.

ZELIZER, Viviana. Circuits in economics life. In ZELIZER, Viviana. Economics lives. New York: Princeton University Press, 2010a. 
- A economia do Care. Civitas Revista de Ciências Sociais, v. 10, n. 3, p. 376391, 2010b.

- Monétisation et vie sociale. Le Portique, n. 19, p. 2-11, 2007.

- Argent, circuits, relations intimes. Enfances, Familles, Générations, n. 2, p. 93-113, 2005a.

- The purchase of intimacy. Princeton (NJ): Princeton University Press, 2005b.

- O significado social do dinheiro - dinheiros especiais. In: MARQUES, Rafael; PEIXOTO, João. Os trilhos da sociologia econômica. Portugal: Celta, 2003.

- La construction des circuits de commerce: notes sur l'importance des circuits personnels et impersonnels. In SERVER, Jean-Michel ; GUÉRIN, Isabelle. Exclusion et liens financiers. Rapport du Centre Walras. Economica, p. 425-429, 2002.

WEBER, Max. Economia e sociedade. v. 1. Brasília: Editora UnB, 2000. 